\title{
Environmental Education: Investigative Activity with Students of Education Young and Adults
}

\author{
Sirlene Nunes Araujo \\ Graduate student in science education \\ through research at the Federal University \\ of Minas Gerais
}

\author{
Heslley Machado Silva \\ $P h D$ in education from the Federal \\ University of Minas Gerais Teacher and \\ researcher at the University of Itauna and \\ University Center of Formiga/ MG
}

\begin{abstract}
This research its aim is to analyze the efficiency of an instructional sequence (SD) with students and young adults (EJA) education. First there was the hypothesis that the students of this type of studies are poorly educated on environmental issues. The methodology used in this work was a qualiquantitative study, based on a case study. The chosen were students of EJA with age between of 18 and 59 years old in a public school in the city of Sete Lagoas, MG. Data collection occurred through observations, lecture, lesson video, debates and a structured questionnaire. The investigation of the data was made from observations and inferences based on the answers of the questionnaire. In addition to this, it was made analysis of the educational booklet. The final analysis of the results of the questionnaire showed that the public needs more education in relation to Environmental Education. Through him, were could infer that more than $75 \%$ of students do not see themselves as agents of environmental damage and also that around 25\% showed worry for the environment. At the end of the survey, it was possible to observe attitudes, habits and practices that demonstrate the need for greater awareness of environmental issues. It has been shown that $S D$ is an efficient way to disseminate the practice of EA and that the $S D$ can be considered an efficient means of disseminating the practice of EA since it led the students to reflect and propose changes in their own attitudes.
\end{abstract}

\section{Introduction}

Discuss issues related to the environmental theme is critical, this approach should begin in early childhood education and continue throughout the life of an individual student, to form more aware and participatory citizens.

Since the industrial revolution, when it noticed the increase in pollution and its impact on nature, began a search for plausible environmental alternatives that mitigate the damage caused by the advance of industrialization. In 1972, the United Nations - UN convened the Conference on Environment in Stockholm (Sweden). Where representatives from various countries discussed for the first time the importance of conservation and wise use of natural property [1].

Regarding the Environmental Education (EE) in international discussions, and urgent measures needed to be taken for the formation of environmental awareness that minimizes human damage to nature, began in 1975 in Belgrade, the International Environmental Education seminar. At this meeting targets for environmental education, which proposes that it should be multidisciplinary and integrated, respecting regional differences have been defined [2].

Environmental education as a curricular component is in accordance with the declaration of Tbilisi, and would then enable the individual to understand the main environmental problems of the contemporary world. "This kind of education should also provide technical expertise and the necessary qualities for the betterment of life and the protection of the environment, sticking to ethical values" [3].

In the context of discussions on the topic in 1992 was held in Rio de Janeiro, Brazil, the United Nations Conference on Environment and Development. Where to put it directly on the public agenda in a way that had hitherto not been taken [1]. Thus, after this course is no longer possible to think of development of a society without thinking on environmental sustainability. Given the necessity that the subject of EE extrapolate the school learning environment and become a social transformation tool, emerged norms and laws that guarantee the right to information, training and awareness of the individual as causative agent of environmental damage.

In the context of normalization for action to promote environmental education in schools can cite chapter VI of the Constitution of the Republic of Brazil . In this chapter, it is stated that it is the duty of the state to promote environmental education at all 
levels of education and public awareness of the preservation of the environment [4].

Moreover, it can be mentioned in 21 international schedule, in Chapter 36 that the presentation of the objectives, once said that one should strive to facilitate access to education in environment and development, linked to social education, from the age primary school to adulthood in all population groups [1].

The National Curriculum Guidelines - NCP of Natural Sciences, there is the guidance that students should be able to realize-members, dependents and environmental change agents, identifying its elements and the interactions between them, actively contributing to the improvement of the environment [5].

Corroborating this, the Common Basic Contents CBC - Minas Gerais, of Natural Science for Elementary Education, bring in Main Topic I Environment and Life, content guidelines to be developed in different teaching phases related to the theme environment [6]. As the Biology of CBC, the same state, bringing the main theme Energy, with the axes associated with biodiversity, materials and modeling, which presents the theme 1 (Web of Life) topic 21 (Human populations and their challenges) [7].

The environmental issues in the $\mathrm{CBC}$, in both levels of education is seen as a cross-cutting issue, that is, should be incorporated into existing areas and school educational work [8]. For another hand, the transversal allows the subject to be inserted into various themes, thus providing a favorable research environment.

\section{The Youth and Adult Education and Environmental Education}

Environmental education theme is widely discussed in the educational environment, however, still needs to be disclosed to students of AYE. This type of education established in 1988 by the federal constitution and consolidated in 1996 by LDBEN as a right, an essential element for building a more just society, based on the principle to guarantee the exercise of citizenship [9].

Article 32 of the LDBEN establishes the objectives of this type of education: the domain of reading, writing and arithmetic; the understanding of the natural and social environment, the political system, technology, the arts and social values; and the strengthening of family ties, solidarity and mutual tolerance, indispensable to social life [9].

"The students of the Youth and Adult Education are individuals within the world of work, possessed of a school career marked by some failures and exclusion that caused the motivation in the classroom, leading to withdrawal for schooling" [10].
In the study of Bertolino, students of EJA pointed out as reasons that led them to go back to school: $40 \%$, improvement of life; $30 \%$ job better and assist child of school age; $20 \%$, industry demand and $10 \%$ search for a better job to raise self-esteem [11]. Showing thus the educational importance of sport and also suggesting the need for appropriate curriculum design to the public.

Education or teaching applied to adults began shortly after World War II [12] [13]. Due to two factors, the first linked to the emergence of mass social movements, and the other, the process of formation and consolidation of school systems.

The International Conference on Adult Education, held in 1960 in Montreal, Canada, marked the beginning of the search for economic development of countries through popular education [13]. In Brazil, this process of adult education was remarkable in the government of Jânio Quadros in 1961, with the creation of the Basic Education Movement (BEM)(MEB) and the National Mobilization Against Illiteracy(NMAI) (MNCA), devised by Paulo Freire.

Teaching adults is different from teaching the children because they already have a empirical knowledge baggage that makes them able to discuss some issues based only on common sense, as exposes Pinto, they are already acting as educated, only not literate way, educated [14].

EA must be worked out from the context of the reality of the subjects with the world, with your life experience. Carvalho in their work, defines two types of EA, behavioral and popular, the first of which deals with the awareness of urgency with respect to environmental problems, and the second is a political act in the broad sense, as a social practice of citizenship formation [15].

Given the importance of preparing more active and critical individuals on issues related to the environment, it is proposed here a survey, from a research practice, which aims through coordinated activities in the classroom to present and develop the theme with students of the Youth and Adult Education (YAE) was expected that with this, students develop problem-solving skills.

Therefore, it's necessary to develop students with the concepts such as sustainability, environmental education and socialization. The student should feel responsible and transforming agent of society as a whole.

It was proposed that through a didactic sequence containing debates and lectures, students are able to reflect their attitudes toward environmental issues and are able to propose measures that represent a change in attitude to the school community and society in general through the production and distribution of educational little letters about the subject. 
This work aims to verify the effectiveness of a teaching sequence as investigative activity with students of EJA, besides knowing the views of students on concepts of environmental education and also help to improve the environmental awareness through the development of concepts such as sustainability and environmental responsibility.

\section{Material and Methods}

This work was carried out with students of the Youth and Adult Education, aged between 18 and 65 years, a school that belongs to the public network of the state of Minas Gerais and is located in Sete Lagoas, a town located approximately $70 \mathrm{~km}$ the capital Belo Horizonte, Brazil. The city's main economic activities steel, automotive and beverage industry also has experienced a population increase. Together these factors cause pressure on the environment of the region.

These students are most neighbors to school, working in township enterprises in various branches such as steel, automotive, trade, some retired and some still housewives. Are lower-class people, who seek the continuation of studies, improvements in the working and social life, and even the return to studies increases self-esteem and enables them to feel useful in society.

This study presents a qualitative and quantitative way, and studied the effectiveness of an investigative activity, through a didactic sequence and thus observe the conceptual evolution of the students on the experience of this activity.

For Souza the conceptual evolution a gradual and complex order process requires awareness and evolution of thought. This is only possible after learning [16].

These students participated in a didactic sequence of education with the theme challenges facing humanity: change of attitude.

This theme was proposed to meet the guidelines of the Common Basic Contents - CBC biology of Minas Gerais for the third year of high school class [7]. For the sequence there were four classes fifty minutes each, the first was made a general approach to the topic, which presented slides to introduce the topic. In the second class we applied the questionnaire "environmental footprint", this practice was interesting because the survey questions are related to the daily lives of the students, with their lifestyle and consumption [17]. In the third period there was a lecture on "energy efficiency" issued by an undergraduate student in Electrical Engineering from the University of Sete Lagoas center.

In the last class there was a debate in groups, culminating in the development of an educational booklet with tips conscious use of natural resources, water, light, proper disposal of waste, in school and in the community.

The investigative purpose of this study involved the presentation of the subject, the exposure problem situations related to the theme, discussions and presentation of concepts learned by the students during SD, this organizational proposal was based, however adapted from Kruger and milk work who discussed the theme Rio +20 , as shown in the table below [18].

Table 1. SD Diagram: humanity's challenges. Research data: Environmental education: an investigative activity with Education students Youth and Adult

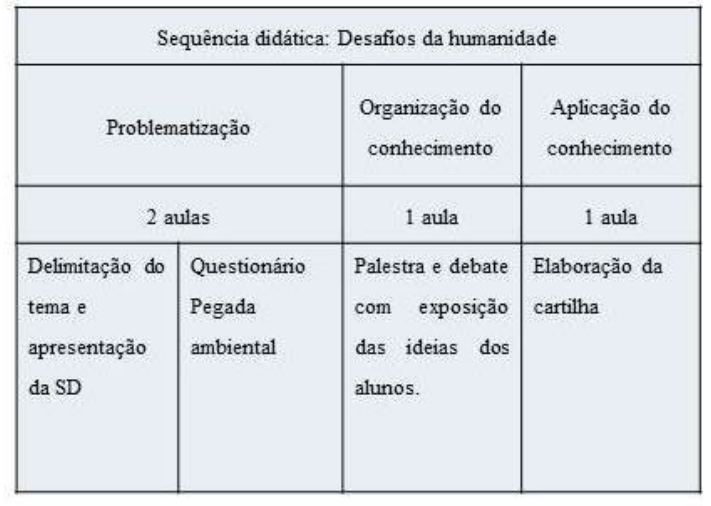

All SD was guided by the problem situation around the question: how to face the challenges of humanity in relation to the environment? Along the $\mathrm{SD}$, it was expected that students develop conceptual, proposing sustainability tips to the school environment, and the community surrounding the school. It is hoped also that these tips serve for reflection and change of attitudes of the students. So, as talks Sabino and Sebim attitudes, habits and beliefs influence the way of conceiving and living preservation practices [19].

After obtaining the data, these were compiled in a spreadsheet on the computer program Office (Excel), where the calculations of percentages were made, and still, the data were compared with the previously suggested in the questionnaire on environmental footprint. The other observation data and each step in the sequence were compared to studies of other authors as described throughout this study.

The evaluation was continuous throughout the implementation of the instructional sequence, considering all activities: questionnaire, discussion, preparation of brochures and presentation of results in the form of primer.

The booklets were the main form of evaluation, was considered cognitive development in the area, students cite as improvement measures for the community school items mentioned in the talk on 
energy, was also considered quotes about conscious use of water and still the group's view on important actions related to the school and the community.

\section{Results and Discussion}

It is important to report the functions of each in a $\mathrm{SD}$, because the teacher as a coordinator of activities, only directed the debates and guided in the preparation of textbooks, as students were active actors who captured the information, transcribed for the role, for their speeches and synthesize all the result that was indeed the playbook. This is important to distinguish the roles is reported by Nascimento et. al. when these authors analyze the construction and evaluation of SD in the teaching of biology [20]. The intention of the SD was to stimulate and enrich the discipline to these students and also get them to reflect on their own attitudes towards the subject.

Students were involved and engaged in the work. During the sequence on the first class where a general approach to the subject was made, the students could discuss with the teacher the most frequent environmental issues at that time they realized that in the city where they live problems are also common and that more awareness is needed and participation of the population as a whole. In the second class when it was applied the questionnaire "environmental footprint", also showed interested because Quiz questions are related to the daily lives of the students, with their lifestyle and consumption in the end it was proposed that in accordance with the symbolic value of the environmental footprint the student should plant a tree, to contribute to the environment. With this questionnaire, we obtained 27 participants.

The questionnaire itself suggested a sum according to the responses per participant, and, if the student answered the "A" marked one (1) point to the "B" marked three (3) points to the "C "five (5) points and the letter" D ", seven (7) points. The interpretation of this sum was suggested in the questionnaire, there is no right or wrong answers or an expected standard. Thus, at the end of injection was made the sum of answers per student and the results were analyzed by percentage (Figure 1 ).

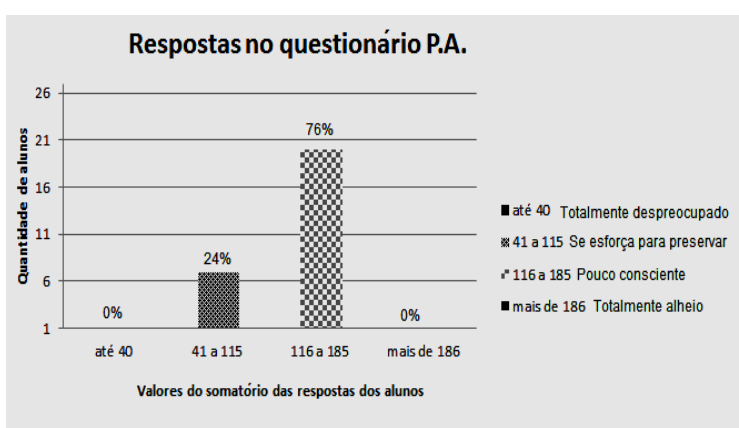

Figure 1. Representation of the sum of answers from the Environmental Footprint questionnaire. Research data: Environmental education: an investigative activity with Education students Youth and Adult

In the third class where there was a lecture on "energy efficiency" before starting the lecture the teacher asked a lot of attention to the hints that would be given to energy saving, that this knowledge would be used soon, students show interest and curiosity with the importance to save energy at home, it can be good for everyone and not only for the economy itself.

In the last class there was a debate in groups, culminating in the development of an educational booklet. The booklets formulation led the students to draw up measures that they themselves need to put in their habits. . The material produced was set at school murals, which further motivated the quality of work produced.

By the time the booklets of the groups were made compatible in only one to represent the general idea of the class. Students realized how they had developed mutual awareness, as many of the items numbered in a group have also been cited by other, which facilitated the production of a single primer. This study allowed pedagogical inferences that are important to the current teaching practices. Especially with regard to education provided to young people and adults, as the sport is struggling both teaching material, appropriate practices, as trained professionals.

\section{Conclusion}

Along the SD, it was possible encourage critical thinking that leads to a better social participation and also develop concepts such as sustainability and environmental responsibility that culminated in the production of an educational booklet (Figure 2).

This investigative activity was considered efficient to raise awareness of adult education students. For these students perceived themselves as potential causative agents of environmental damage and concluded that the transformation of the whole from the own change of attitude is possible. Students participated with commitment of activities, it is 
important to emphasize that the didactic proposal highlighted the key role of each for environmental education, which was noticeable in students during the sequence.

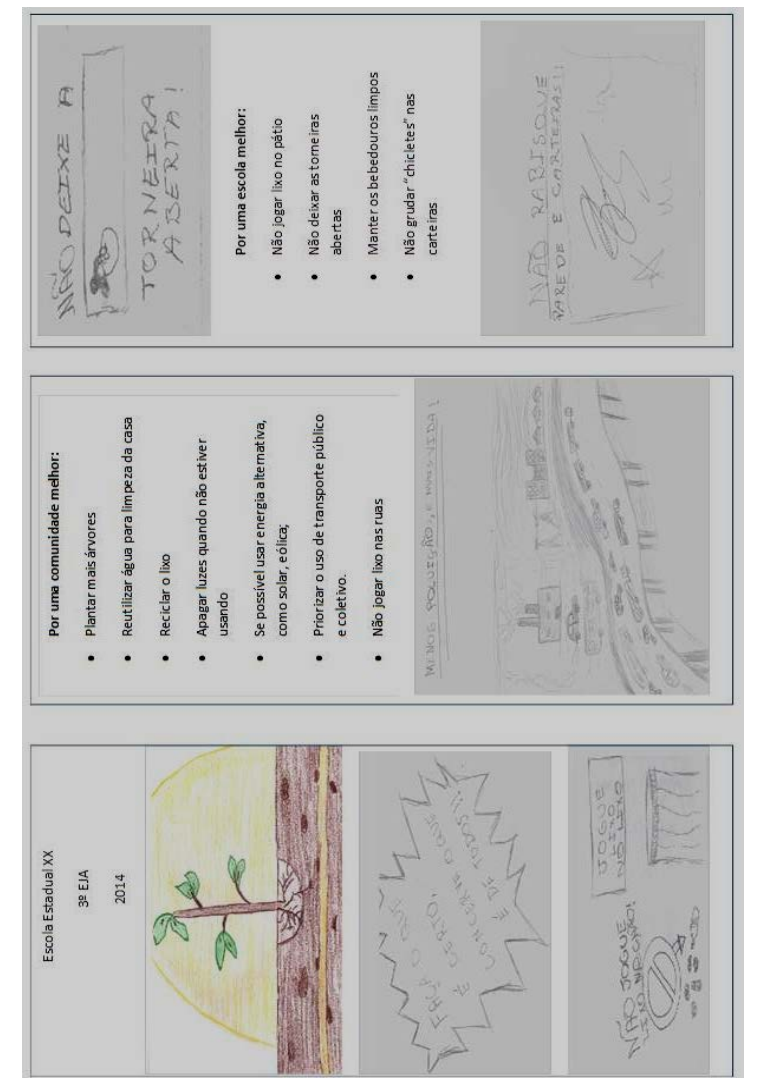

Figure 2. Unified Primer. Research data:

Environmental education: an investigative activity with students of the Youth and Adult Education

\section{References}

[1] United Nations - UN. The UN and the environment. Available in <http://www.onu.org.br/a-onu-em-acao/aonu-eo-meio-ambiente/> access 18/09/2013.

[2] GUIMARÃES, Mauro. The environmental dimension in education. Campinas, Sao Paulo, Ed. Papirus. (Magisterium Collection: Training and educational work), 1995.

[3] BRAZIL. Ministry of the Environment. Declaration of Tbilisi, $1977 . \quad$ Available at $<$ http://www.mma.gov.br/port/sdi/ea/deds/pdfs/decltbilisi.p df $>$ access 06/04/2014.

[4] BRAZIL. Constitution (1988). Constitution of the Federative Republic of Brazil: promulgated on 5 October 1988. Organization of text: Juarez de Oliveira. 4. ed. Sao Paulo: Saraiva, 1990. 168 p.

[5] BRAZIL. Primary Education Department. National Curriculum Standards: Natural Sciences / Department of Elementary Education. - Brasilia, 1998. 138p.
[6] MINAS (2006). Secretary of State of Education of Minas Gerais. Common Basic Contents (6th to 9th grade). Proposed curriculum: Science Elementary School, 2006. 68p. Available in <http://www.educacao.mg.gov.br> Access on 18 September 2013.

[7] MINAS (2007). Secretary of State of Education of Minas Gerais. Common Basic Contents (1st to 3rd year). Proposed curriculum: Biology High School. 68p. 2007. Available at $<$ http://www.educacao.mg.gov.br $>$ Access on 18 September 2013.

[8] BRAZIL. Primary Education Department. National curriculum guidelines: presentation of cross-cutting themes / Primary Education Department. - Brasilia, 1997. 146p. Available in $<$ http://portal.mec.gov.br/seb/arquivos/pdf/livro081.pdf > Access November 19, 2014.

[9] BRAZIL. Law No. 9394, OF 20 DECEMBER 1996 establishes the guidelines and bases of national education. Available <http://www.planalto.gov.br/ccivil_03/leis/19394.htm> Access 05 November 2014.

[10] SESC - Social Service of trade. Network Education. Resumes in adult education: knowledge and practices of educators. - Rio de Janeiro: SESC, National Office, 2011. 258 p. Available in <www.sesc.com.br/wps/wcm /.../ Education + in + Network + - + EJA.pdf $>$ Access on 15 September 2014.

[11] BERTOLINO, Maria Lucia. The Environmental Education Youth and Adult Education. Magazine Systemic Teaching. Federal University of Rio Grande. Vol. 6, Jul. / Dec. 2007. 21p. Available in <http://www.seer.furg.br/redsis/article/view/1237/532> Access on Sep 142014 onwards.

[12] Knowles, Malcolm Shepherd. The modern practice of adult education. The Adult Education Company. Cambridge. 7th ed. New York. 1913. Available at $<$ http://www.umsl.edu/ henschkej/articles/a_The_\%20Mo dern_Practice_of_Adult_Education.pdf $>08$ july 2014 access.

[13] CANARY, Rui. Adult education: a field and a problem. Ed. Educa. Lisbon. 1999. 152p.

[14] PINTO, Alvaro Vieira. Seven lessons on adult education. 11 Edition. São Paulo. Cortez, 2000.

[15] CARVALHO, Isabel Cristina de Moura. What Environmental Education? Some reflections on environmental education and extension. Rev. Agroecology and Sustainable Rural Development. Porto Alegre, v.2, n.2, April / jun.2001

[16] SOUZA, Flavia Burdzinski of; Maldaner, Otavio Aloisio. The conceptual significance in the early education of children. In: Research Seminar in education in the South region 2012. 16p. Available in $<$ http://www.ucs.br/etc/conferencias/index.php/anpedsul/9 anpedsul/paper/viewFile/206/344> Access November 19, 2014. 
[17] BRAZIL. Federal University of Bahia. Environmental footprint questionnaire. Available in $<$ http://www.ufbaecologica.ufba.br/arquivos/questionario_ pegada_ambiental_Final.pdf $>$ access 28/3/14.

[18] KRUGER, Joelma Goldner; MILK, Sydney Quezada Meireles. Instructional sequence of science to discuss the river theme +20 : historical critical approach in search of the scientific literacy of high school students. In: III national education Symposium on science and technology. Ponta Grossa, Paraná, 2012. 12p. Available in <www.sinect.com.br/2012/down.php?id=2717\&q=1>

Access on 31 August 2014.

[19] Sabino, Sabrina Marconsini; SEBIM Charlini Contarato. Statistical analysis of social representations about environmental preservation. In: Proceedings - VI Day of scientific initiation, development and innovation. Federal Institute of the Holy Spirit. 2011. 4p. Available in $<$ http://pse.ifes.edu.br/prppg/pesquisa/jornadas/jornada_20 10_2011/anais/T2349.pdf $>$ Access from 01 November 2014.

[20] BIRTH, Lia Midori Meyer; Guimarães, Maria Daniela Martins; El-Hani, Charbel Niño. Construction and evaluation of didactic sequences for the teaching of biology: a critical review of the literature. In. VII National Research Meeting in science education. Florianópolis, 2009. Available in <http://posgrad.fae.ufmg.br/posgrad/viienpec/pdfs/1002 pd f> Access on 31 August 2014.

\section{Acknowledgements}

In the pedagogical team from the State School Professor Rousset, the UFMG ENCI team and everyone who contributed to this work directly and indirectly. 